\title{
Comparison of corneal sensitivity, tear function and corneal staining following laser in situ keratomileusis with two femtosecond laser platforms
}

\author{
This article was published in the following Dove Press journal: \\ Clinical Ophthalmology \\ 22 March 2013 \\ Number of times this article has been viewed
}

\author{
Andrea Petznick' \\ Annabel $\mathrm{Chew}^{2}$ \\ Reece C Hall ${ }^{2}$ \\ Cordelia ML Chan ${ }^{2}$ \\ Mohamad Rosman ${ }^{1,2}$ \\ Donald Tan ${ }^{1-3}$ \\ Louis Tong ${ }^{1-4}$ \\ Jodhbir S Mehta ${ }^{1-3}$ \\ 'Singapore Eye Research Institute, \\ Singapore; ${ }^{2}$ Singapore National Eye \\ Centre, Singapore; ${ }^{3}$ Department of \\ Ophthalmology, Yong Loo Lin School \\ of Medicine, National University \\ of Singapore, Singapore; ${ }^{4}$ Duke-NUS \\ Graduate Medical School, Singapore
}

Correspondence: Jodhbir S Mehta Singapore National Eye Centre, II Third Hospital Avenue, Singapore 16875 I

Tel +65 62277255

Fax +65 62277290

Email jodmehta@gmail.com
Purpose: To evaluate longitudinal changes in corneal sensitivity, tear function, and corneal staining in patients who underwent laser in situ keratomileusis (LASIK) using two different femtosecond lasers.

Methods: In a prospective, randomized clinical trial, contralateral eyes of 45 patients underwent flap creation by either VisuMax or IntraLase ${ }^{\mathrm{TM}}$ femtosecond laser. Corneal sensitivity, tear break up time (TBUT), Schirmer's test, and corneal fluorescein staining were assessed preoperatively and at 1 week, 1 month, and 3 months postoperatively.

Results: There were no statistical differences in any clinical outcome measure between the two femtosecond lasers $(P>0.05)$, although there was a trend towards slightly lower reductions for corneal sensitivity and TBUT in VisuMax-operated eyes. Overall, corneal sensitivity was significantly reduced at 1 week $(P<0.05), 1$ month $(P<0.001)$, and 3 months $(P<0.001)$ postoperatively. A significantly greater reduction of corneal sensitivity was noted in eyes with a myopic spherical equivalent of -6.00 diopters (D) to $-11.25 \mathrm{D}$ as compared with eyes that had a relatively lower level of myopia of less than $-6.00 \mathrm{D}(P<0.001)$. TBUT and Schirmer's test values were significantly diminished at 1 week postoperatively $(P<0.04)$. Overall, corneal staining was significantly increased at 1 week postoperatively $(P<0.001)$. The level of myopia did not significantly affect postoperative changes in TBUT, Schirmer's test values, or corneal staining $(P>0.05)$.

Conclusion: This study showed that changes in corneal sensitivity, tear function, and corneal staining were statistically similar in LASIK using VisuMax and IntraLase femtosecond lasers for flap creation. However, the trend towards faster recovery of corneal sensitivity and TBUT observed in VisuMax-operated eyes may be attributable to improved technical specifications.

Keywords: femtosecond laser, corneal sensitivity, tear film break-up time, Schirmer's, corneal staining

\section{Introduction}

Laser in situ keratomileusis (LASIK) is the most common procedure for correction of myopia. ${ }^{1}$ Despite technological advancements, LASIK still has unresolved problems, such as reduced tear function and increased corneal staining (indicating ocular surface epitheliopathy).,3 Tear function is closely related to corneal sensation, and cutting of a flap during LASIK reduces corneal sensitivity, as corneal nerves are truncated. ${ }^{4}$

Femtosecond lasers have become a popular option to create corneal flaps, due to greater efficacy, predictability, and safety. The IntraLase ${ }^{\mathrm{TM}}$ femtosecond laser (Abbott Medical Optics Inc, Santa Ana, CA, USA) was the first laser introduced into the 
refractive surgery market. New technological developments have led to the introduction of a range of femtosecond lasers, including the VisuMax (Carl Zeiss Meditec, Jena, Germany). Newer platforms allow one to create smaller flaps, use higher repetition rates, and lower laser pulse energy as well as utilize different suction methods that may have less adverse effects on corneal nerves and tear function. The VisuMax laser, with a higher repetition rate, utilizes lower energy and corneal suction, while the IntraLase laser, with a lower repetition rate, uses higher energy and conjunctival suction.

Dry eye is the major predicament associated with LASIK. ${ }^{5}$ It has been demonstrated that femtosecond flaps have a lower incidence of LASIK-associated dry eye as compared with flaps created by microkeratomes. ${ }^{6}$ However, it is not known whether the newer femtosecond lasers have an even greater potential to better preserve tear function. Hence, this current study aimed to investigate whether the use of the VisuMax laser for flap creation was equivalent to the IntraLase laser in terms of corneal sensitivity, tear film break up time (TBUT), Schirmer's test, and corneal fluorescein staining.

\section{Methodology Study design}

This study was a prospective, contralateral paired-eye, clinical trial (ClinicalTrials.gov identifier: NCT01252654) comparing corneal sensitivity, tear function, and corneal staining, following femtosecond LASIK, in myopic patients at the Singapore National Eye Centre. The study was approved by the Singapore Eye Research Institute Ethics Committee and adhered to the tenets of the Declaration of Helsinki. One of the femtosecond lasers (either VisuMax or IntraLase) was randomly assigned to the first eye, and the alternative technique was used in the contralateral eye. A full LASIK procedure was completed on the first eye before it was performed on the second eye. Procedures were performed by certified and experienced surgeons (JSM, MR, and CMLC).

\section{Patient selection}

Forty-five consecutive patients were enrolled after written informed consent was obtained. Inclusion criteria were a stable myopia prescription for the previous 6 months, best corrected visual acuity of 20/20 or better, a spherical equivalent difference of no more than 2 diopter (D) spheres in both eyes, and a minimal corneal thickness of at least $500 \mu \mathrm{m}$. Patients without contact lens-related problems ceased wear of soft contact lenses for at least 2 weeks and rigid gas permeable lenses for at least 3 weeks, to obtain stable keratometry readings.
Patients were excluded if they had corneal or anterior segment pathology, retinal degeneration, keratoconus, previous ocular surgery, a history of herpes zoster ophthalmicus or herpes simplex keratitis, diabetes mellitus, autoimmune disease, severe dry eye, connective tissue disease or significant atopic syndrome, or were undergoing chronic systemic corticosteroid or immunosuppressive therapy. Patients with intraocular pressure of more than $21 \mathrm{mmHg}$ or a history of a steroid-induced increase in intraocular pressure were excluded. This criteria was selected to prevent posterior segment damage, as the intraocular pressure has been shown to rise up to $82 \mathrm{mmHg}$ during the suction procedure. ${ }^{7}$

Preoperative and postoperative evaluation was comprised of uncorrected distance visual acuity, manifest refraction, corrected distance visual acuity, and slit lamp biomicroscopy. Additionally, preoperative evaluation included noncontact tonometry (NT-3000 Auto Non Contact Tonometer; NIDEK Co, Ltd, Aichi, Japan), pachymetry (Orbscan ${ }^{\circledR} I I z ;$ Bausch and Lomb, Rochester, NY, USA), and fundus assessment.

\section{Surgical technique}

Corneal flaps were created with a $500 \mathrm{kHz}$ VisuMax laser or a $60 \mathrm{kHz}$ IntraLase laser. The mean targeted flap diameter for VisuMax was $8.4 \pm 0.0 \mathrm{~mm}$ and for IntraLase was $8.9 \pm 0.2 \mathrm{~mm}$. The targeted flap thickness was 110 to $115 \mu \mathrm{m}$, for both techniques. The laser parameters for the VisuMax were: small (S) cone, superior hinge, side-cut angle 85 degrees, hinge angle 70 degrees, laser-bed energy 0.16 to $0.165 \mu \mathrm{J}$, spot separation $1.5 \mu \mathrm{m}$ (rim) and $4.8 \mu \mathrm{m}$ (lamellar), and line spot separation $1.5 \mu \mathrm{m}$ (rim) and $4.8 \mu \mathrm{m}$ (lamellar). The laser parameters for the IntraLase were: standard suction, superior hinge, side-cut angle 70 degrees, hinge angle 50 degrees, laser-bed energy $0.95 \mu \mathrm{J}$ (range 0.92 to $1.08 \mu \mathrm{J}$ ), pocket enable on, pocket width $0.25 \mathrm{~mm}$, pocket start depth $230 \mu \mathrm{m}$, pocket tangent $7 \mu \mathrm{m}$, and radian spot separation $6 \mu \mathrm{m}$.

Stromal tissue laser ablation was performed with the WaveLight ${ }^{\circledR}$ Allegretto Eye-Q $400 \mathrm{~Hz}$ excimer laser system (Alcon Laboratories Inc, Fort Worth, TX, USA), using the wavefront-optimized treatment profile. The attempted optical zone was $6.50 \mathrm{~mm}$, and the target refraction was plano spherical equivalent.

All eyes were treated with nonpreserved moxifloxacin hydrochloride $0.5 \%$ eye drops (Vigamox ${ }^{\circledR}$, Alcon Laboratories Inc) and dexamethasone $0.1 \%$ eye drops (Maxidex ${ }^{\mathrm{TM}}$, Alcon Laboratories Inc), four times daily for 1 week. Nonpreserved artificial tears (Tears Naturale Free ${ }^{\circledR}$, Alcon Laboratories Inc) were prescribed postoperatively as follows: hourly for the 
first 7 days, eight times daily for 1 week, five times daily for 1 month, and then four times daily for the remaining period of the study. However, if this regimen was not sufficient, the dosage was adjusted to the patient's symptoms.

Postoperative follow-up visits were at 1 day, 1 week, 1 month, and 3 months. All examiners evaluating patients postoperatively were masked.

\section{Clinical outcome measures}

The outcome measures were comprised of corneal sensitivity, TBUT, Schirmer's test, and corneal fluorescein staining. Measurements for corneal sensitivity were taken preoperatively at 1 month and at 3 months postoperatively, while other outcome measures were collected at each visit, except at 1 day postoperatively. TBUT and corneal staining were evaluated after instillation of fluorescein. TBUT was defined as the time taken (in sec) for the first dark spot to appear on the cornea from the moment of eye opening. The cornea was assessed using fluorescein dye and divided into three horizontal zones (upper, middle, and lower). Positive staining scores were: 0 (no staining), 1 (some staining), 2 (staining in more than half of the area), and 3 (staining in the whole zone). Staining scores were added from each zone, for a total staining score ranging from 0 to 9 . Corneal sensitivity was measured in five zones, using the CochetBonnet esthesiometer (Visionix Luneau, Paris, France). The patient was positioned on an ophthalmic chin and brow rest of a slit lamp, and a nylon monofilament of $6.00 \mathrm{~cm}$ was perpendicularly advanced to the central cornea. The filament was shortened in $0.50 \mathrm{~cm}$ increments, if the patient did not feel the filament. Measurements (in $\mathrm{cm}$ ) were repeated in the superior, inferior, temporal, and nasal zones. The reduction of corneal sensitivity was equal in all zones, and the average values were reported. Tear production was tested by Schirmer's tests (Sno strips ${ }^{\circledR}$, Bausch and Lomb), without anesthesia, and the length of wetting (in $\mathrm{mm}$ ) within 5 minutes was recorded.

\section{Statistics}

Sample size calculations were based on the efficacy of myopic correction. ${ }^{8}$ To achieve $80 \%$ power at alpha of $5 \%$, using a noninferiority limit of $92 \%$ and assuming success rate of $75 \%$, a sample size of 41 patients was required in each group to show noninferiority. As this trial was designed to be a contralateral paired-eye study, a total of 45 patients were recruited to allow for withdrawal.

A paired $t$-test was used to compare the preoperative parameters, ie, spherical equivalent and keratometry. The differences in clinical outcomes over time and between femtosecond platforms at various visits were analyzed with a mixed linear model, using the SPSS package (Version 17.0, IBM, Armonk, NY, USA). The dependent variables were corneal sensitivity, TBUT, Schirmer's test, and corneal staining, while fixed factors included visit, femtosecond laser, and level of myopia. The levels of myopia were defined as low myopia $(<-6.00 \mathrm{D})$ and high myopia $(\geq-6.00 \mathrm{D})$. The operating surgeon, patient age, and patient gender were included as covariates, to model their influence on each dependent variable. Pearson's correlations were performed, to identify significant interactions between refractive status and clinical measures. A significance level (alpha) of 0.05 was used.

\section{Results \\ Demographics}

Table 1 shows patient data and preoperative ocular parameters. The study enrolled 45 patients, with a mean age of 28.8 years old (range 21 to 39 years), and 56\% were females. The preoperative spherical equivalent for all eyes, expressed as mean \pm standard deviation, was $-4.93 \pm 2.09 \mathrm{D}$ (range 11.25 to $-1.375 \mathrm{D})$, and keratometry was $44.09 \pm 1.70 \mathrm{D}$ (range 40.20 to $48.80 \mathrm{D}$ ). Forty-five patients were followed up for 1 month and 39 patients for 3 months.

\section{Refractive outcomes}

There was no difference in visual acuity between VisuMax- or IntraLase-treated eyes. The uncorrected distance visual acuity was significantly improved in both platforms $(P<0.001)$.

\section{Clinical outcome measures}

Corneal sensitivity following LASIK was not statistically different when both femtosecond platforms were compared $(P=0.90)$. However, corneal sensitivity was dependent on preoperative levels of myopia $(P<0.001)$. The data was split into high and relatively low myopia. A trend towards slightly greater reduction was observed in IntraLase-operated eyes, with myopia less than $-6.00 \mathrm{D}$ at the 1 month postoperative visit $(P>0.05)$ (Table 2). Over time, corneal sensitivity was generally decreased for both techniques at 1 week $(P<0.04)$, 1 month $(P<0.001)$, and 3 months $(P<0.001)$ after surgery.

The TBUT and Schirmer's values were significantly reduced at 1 week $(P<0.05)$, but there was no difference between the two femtosecond lasers at any visit $(P>0.05)$ (Tables 3 and 4). Due to a low number of eyes, a statistical comparison for TBUT based on myopia could only be performed in eyes with myopia less than $-6.00 \mathrm{D}$. A consistent, 
Table I Patient data and preoperative ocular parameters

\begin{tabular}{|c|c|c|c|c|c|c|}
\hline \multirow{2}{*}{$\begin{array}{l}\text { Flap } \\
\text { creation }\end{array}$} & \multirow{2}{*}{$\begin{array}{l}\text { Mean age, range } \\
\text { (years) }\end{array}$} & \multicolumn{2}{|c|}{$\operatorname{Sex}(n)$} & \multirow{2}{*}{$\begin{array}{l}\text { Eyes } \\
\text { (n) }\end{array}$} & \multirow{2}{*}{$\begin{array}{l}\text { Mean SER } \pm \text { SD } \\
\text { (D) }\end{array}$} & \multirow{2}{*}{$\begin{array}{l}\text { Mean } \mathrm{K} \pm \mathrm{SD} \\
\text { (D) }\end{array}$} \\
\hline & & $\overline{\text { Male }}$ & Female & & & \\
\hline VisuMax & $28.8,21-39$ & 20 & 25 & 45 & $-4.94 \pm 2.08$ & $44.16 \pm 1.81$ \\
\hline IntraLase ${ }^{\mathrm{TM}}$ & & & & 45 & $-4.91 \pm 2.09$ & $44.02 \pm 1.61$ \\
\hline$P$-value & - & - & - & - & 0.94 & 0.26 \\
\hline
\end{tabular}

Notes: VisuMax (Carl Zeiss Meditec, Jena, Germany) and IntraLase TM (Abbott Medical Optics Inc, Santa Ana, CA, USA).

Abbreviations: SER, spherical equivalent refraction; SD, standard deviation; K, keratometry; D, diopter.

but not significant, tendency for lower TBUT values was observed with the IntraLase $(P>0.05)$ (Table 4$)$.

Although there was a general and significant increase in corneal staining after LASIK $(P<0.05)$, the staining between both femtosecond lasers was not statistically different at any visit $(P=0.70)$ (Table 5).

\section{Discussion}

This current study investigated, for the first time, whether newer femtosecond lasers have a greater potential to better preserve tear function. We assessed the effect of VisuMax- and IntraLase-created flaps on corneal sensitivity, tear function, and corneal health in myopic patients over a 3-month period. The present study focused on clinical parameters, and detailed refractive outcomes were published elsewhere. ${ }^{9}$

This report showed that both platforms were not statistically different in terms of clinical outcomes. However, a trend towards greater reduction of corneal sensitivity and TBUT was observed in IntraLase-treated eyes.

Overall, a significant reduction in corneal sensitivity following LASIK persisted for up to 3 months postoperatively, with a larger decrease noted in high myopic eyes. Furthermore, significantly diminished Schirmer's and TBUT values as well as increased corneal staining were recorded for up to 1 week postoperatively.

\section{Corneal sensitivity}

It is generally accepted that thick LASIK corneal flaps cause greater damage to corneal nerves than thinner flaps. ${ }^{5,10} \mathrm{In}$ recent years, surgeons aimed to create thinner flaps, of around $100 \mu \mathrm{m}$, to minimize corneal nerve damage and reduce the incidence of LASIK-induced dry eye. Naturally, the process of photoablation to correct the desired amount of myopia plays an important role, ie, a higher target correction of myopia requires deeper ablation, thereby damaging more corneal nerves. ${ }^{11}$ In the current 3-month study, corneal sensitivity did not return to preoperative levels, which concurs with previous investigations that have demonstrated that nerve recovery may take as long as 6 months or even longer. ${ }^{10,12}$

The current study highlighted that a higher level of myopia, corresponding to greater ablation depth, negatively affected corneal sensitivity, which is in agreement with findings of previous studies. ${ }^{11,13} \mathrm{~A}$ detailed analysis in this present study showed that a higher amount of necessary correction reduced corneal sensitivity by up to $44 \%$, while a lower amount of correction diminished sensitivity by about $17 \%$. It has been suggested that larger flap diameters may reduce sensitivity to a higher degree as a result of greater corneal nerve insult. ${ }^{11}$ A slightly greater, but not significant, loss of corneal sensitivity was noted in relatively low myopic IntraLase-treated eyes at 1 month postoperatively, which may have been derived from the larger flap size. The reason for this insignificant finding may be that the difference in

Table 2 Changes over time in corneal sensitivity following VisuMax or IntraLase ${ }^{\text {TM }}$ LASIK

\begin{tabular}{|c|c|c|c|c|c|c|c|c|c|c|c|c|c|c|c|}
\hline \multicolumn{6}{|l|}{$\overline{\text { Preop }}$} & \multicolumn{5}{|c|}{ I month } & \multicolumn{5}{|c|}{3 months } \\
\hline \multirow{2}{*}{$\begin{array}{l}\text { Level of } \\
\text { myopia } \\
\geq-6.00 \mathrm{D}\end{array}$} & \multirow{2}{*}{$\begin{array}{l}\text { Flap } \\
\text { creation }\end{array}$} & \multirow{2}{*}{$\begin{array}{l}\begin{array}{l}\text { Mean } \\
(\mathrm{cm})\end{array} \\
5.9\end{array}$} & $95 \%$ & $\mathrm{Cl}$ & \multirow{2}{*}{$\begin{array}{l}\boldsymbol{P} \\
0.434\end{array}$} & \multirow{2}{*}{$\begin{array}{l}\begin{array}{l}\text { Mean } \\
(\mathrm{cm})\end{array} \\
3.5\end{array}$} & $95 \%$ & & \multirow{2}{*}{$\begin{array}{l}\begin{array}{l}\text { Change } \\
\text { to preop } \\
\text { (\%) }\end{array} \\
-40.7\end{array}$} & \multirow{2}{*}{$\begin{array}{l}P \\
0.335\end{array}$} & \multirow{2}{*}{$\begin{array}{l}\begin{array}{l}\text { Mean } \\
(\mathrm{cm})\end{array} \\
4.0\end{array}$} & $95 \%$ & & \multirow{2}{*}{$\begin{array}{l}\begin{array}{l}\text { Change } \\
\text { to preop } \\
\text { (\%) }\end{array} \\
-32.3\end{array}$} & \multirow{2}{*}{$\begin{array}{l}P \\
0.468\end{array}$} \\
\hline & & & 4.9 & 6.9 & & & 2.4 & 4.6 & & & & 2.8 & 5.1 & & \\
\hline & IntraLase & 5.7 & 4.5 & 7.0 & & 3.8 & 2.4 & 5.1 & -34.3 & & 3.2 & 1.8 & 4.6 & -43.6 & \\
\hline & Eyes (n) & 24 & & & & 21 & & & & & 18 & & & & \\
\hline \multirow[t]{3}{*}{$<-6.00 \mathrm{D}$} & VisuMax & 5.9 & 5.5 & 6.3 & 0.086 & 5.3 & 4.9 & 5.8 & -9.7 & 0.095 & 5.2 & 4.7 & 5.6 & -12.5 & 0.107 \\
\hline & IntraLase & 5.8 & 5.3 & 6.3 & & 4.8 & 4.3 & 5.3 & -17.1 & & 4.9 & 4.4 & 5.4 & -14.8 & \\
\hline & Eyes (n) & 63 & & & & 55 & & & & & 54 & & & & \\
\hline
\end{tabular}

Notes: Estimated mean of corneal sensitivity, lower and upper bound of $95 \%$ confidence interval. VisuMax (Carl Zeiss Meditec, Jena, Germany) and IntraLase ${ }^{\mathrm{TM}}$ (Abbott Medical Optics Inc, Santa Ana, CA, USA).

Abbreviations: LASIK, laser in situ keratomileusis; $\mathrm{Cl}$, confidence interval. 

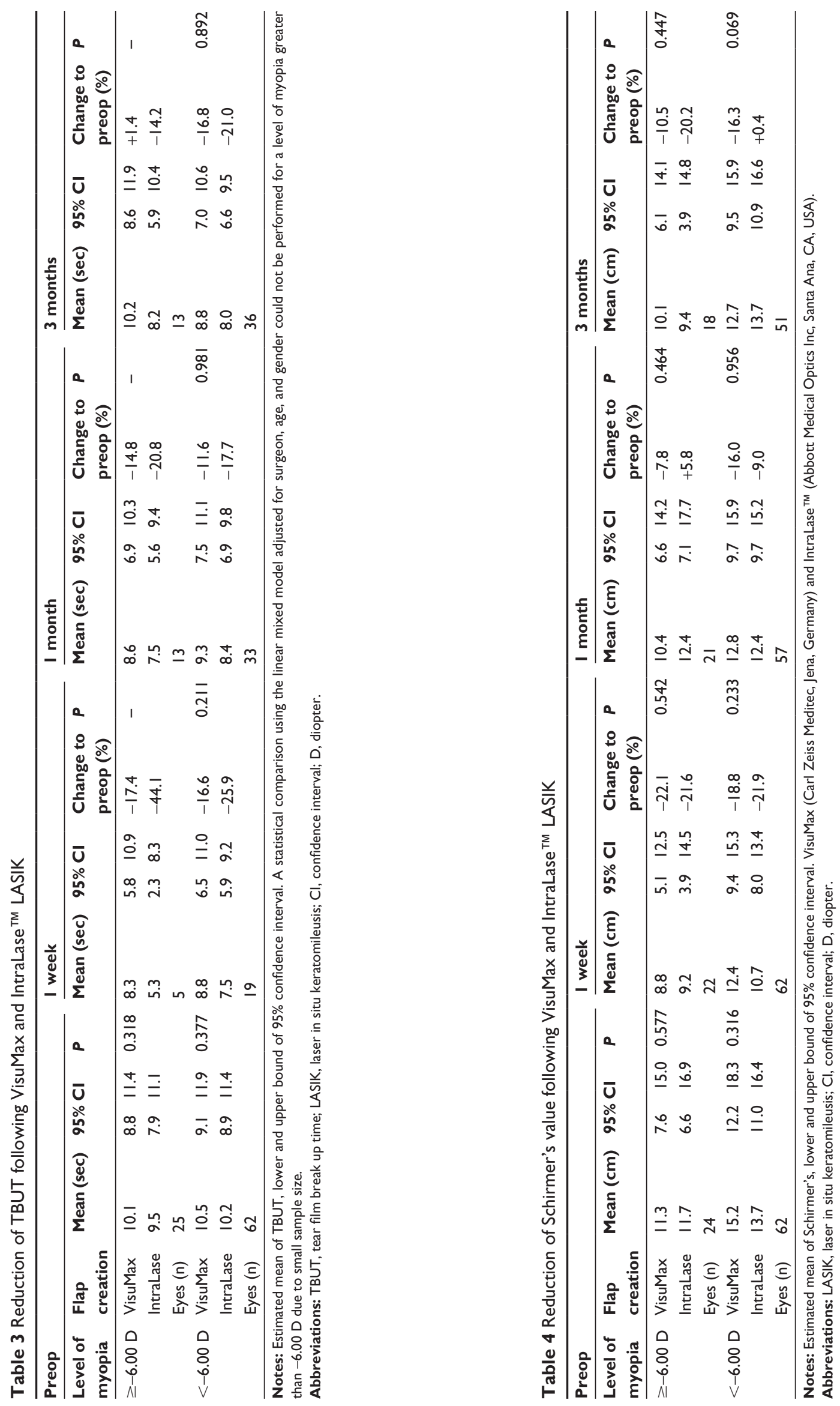
Table 5 Changes over time in corneal fluorescein staining and incidence rates following VisuMax or IntraLase ${ }^{\text {TM }}$ LASIK

\begin{tabular}{|c|c|c|c|c|c|c|c|c|c|c|c|c|c|}
\hline \multicolumn{5}{|l|}{ Preop } & \multicolumn{3}{|c|}{ I week } & \multicolumn{3}{|c|}{ I month } & \multicolumn{3}{|c|}{3 months } \\
\hline $\begin{array}{l}\text { Level of } \\
\text { myopia }\end{array}$ & $\begin{array}{l}\text { Flap } \\
\text { creation }\end{array}$ & Mean & SE & $\begin{array}{l}\text { Incidence } \\
\text { rate (\%) }\end{array}$ & Mean & SE & $\begin{array}{l}\text { Incidence } \\
\text { rate (\%) }\end{array}$ & Mean & SE & $\begin{array}{l}\text { Incidence } \\
\text { rate (\%) }\end{array}$ & Mean & SE & $\begin{array}{l}\text { Incidence } \\
\text { rate (\%) }\end{array}$ \\
\hline \multirow[t]{3}{*}{$\geq-6.00 \mathrm{D}$} & VisuMax & 0.0 & 0.0 & 0 & 0.5 & 0.3 & 38.5 & 0.4 & 0.2 & 30.8 & 0.3 & 0.2 & 18.2 \\
\hline & IntraLase & 0.1 & 0.1 & 8.3 & 0.6 & 0.3 & 16.7 & 0.3 & 0.2 & 25.0 & 0.2 & 0.2 & 20.0 \\
\hline & Eyes (n) & 25 & & & 25 & & & 25 & & & 21 & & \\
\hline \multirow[t]{3}{*}{$<-6.00 \mathrm{D}$} & VisuMax & 0.0 & 0.0 & 3.2 & 0.7 & 0.2 & 35.5 & 0.1 & 0.1 & 6.5 & 0.2 & 0.1 & 21.4 \\
\hline & IntraLase & 0.0 & 0.0 & 0 & 0.9 & 0.2 & 46.9 & 0.2 & 0.1 & 15.6 & 0.3 & 0.1 & 13.8 \\
\hline & Eyes $(n)$ & 65 & & & 65 & & & 65 & & & 57 & & \\
\hline
\end{tabular}

Notes: Estimated mean of corneal staining score \pm standard error. VisuMax (Carl Zeiss Meditec, Jena, Germany) and IntraLase ${ }^{\text {TM }}$ (Abbott Medical Optics Inc, Santa Ana, CA, USA). Abbreviations: LASIK, laser in situ keratomileusis; SE, standard error; D, diopter.

flap diameter of $0.5 \mathrm{~mm}$ between both techniques was too small or that the sample size was not sufficient to show a significant effect. However, a similar finding was made in a study that compared eyes with femtosecond laser- or microkeratome-created flaps. ${ }^{12}$ In that study, the diameter of the microkeratome flaps was generally $0.4 \mathrm{~mm}$ larger. The study could not show differences in subbasal nerve density or corneal sensitivity between the larger microkeratome and the smaller femtosecond laser flaps. ${ }^{12}$

Loss of corneal sensitivity and subsequent LASIKinduced dry eye has been mainly attributed to the LASIK flap. A way of reducing damage to corneal nerves may be to avoid cutting a flap altogether. A recently introduced modification of femtosecond lenticule extraction (FLEx), named small incision lenticule extraction (SMILE), ${ }^{14}$ cuts a refractive lenticule that is manually removed from the cornea through a small incision. Such an alternative keeps most corneal nerves intact and has the potential to significantly improve dry eye symptoms.

\section{TBUT and Schirmer's test}

Truncation of corneal nerves during flap creation interrupts the neuronal feedback mechanism linking the lacrimal gland and cornea. As a consequence of corneal denervation, a reduction in tear secretion and dry eye symptoms may occur. ${ }^{15,16}$ Most studies have confirmed this hypothesis and have reported diminished Schirmer's values for up to 1 week $^{17,18}$ or even 6 months postoperatively. ${ }^{2,19-21}$

The present study did not identify differences between the two femtosecond platforms, but found Schirmer's values that were generally lower 1 week following LASIK as compared with preoperative values. In contrast, some studies found little or no changes in Schirmer's values., ${ }^{3,16,22}$ The reason for this short-term decline in tear secretion is not clear. We observed a decrease in corneal sensitivity for up to 3 months postoperatively, which implies corneal denervation. It may be possible that peripheral and unaffected nerves compensated for the loss of some of the corneal sensation, thereby partially restoring function of the neuronal feedback loop and facilitating lubrication of the ocular surface.

Previous literature is inconsistent in regards to tear film stability following LASIK. It has been reported that TBUT was diminished in both microkeratome- and femtosecond laser-created flaps. ${ }^{2,5,11,20,21,23}$ Some authors found no significant changes in TBUT, ${ }^{16,22}$ while others noted a slight, but insignificant, increase in TBUT, in particular when using femtosecond lasers. ${ }^{17,24}$

The present findings showed that TBUT was significantly reduced 1 week after surgery. In relative contrast to earlier reports that noticed an increased TBUT, we detected TBUT values that appeared to be slightly, but not significantly, lower in the IntraLase-treated eyes as compared with VisuMax. This finding may be explained by the different suction mechanisms used in both platforms. While the IntraLase system applies suction onto the sclera via a suction ring, the VisuMax system creates suction on the cornea via a curved contact glass. The high level of pressure induced by a suction ring onto the sclera has been shown to reduce the number of goblet cells in the bulbar conjunctiva. ${ }^{25}$ The tear film stability may therefore directly be affected by a compromised mucin layer, hence resulting in a slightly less stable tear film, as shown in the IntraLase-treated eyes of the current study.

\section{Corneal staining}

Greater levels of corneal staining may be expected following LASIK, as a result of loss in corneal sensation and subsequent reduced tear secretion as well as increased tear osmolarity. ${ }^{19,26}$ This idea concurs with previous reports. ${ }^{3,5,16,22,23}$ In the present study, corneal staining was elevated at 1 week postoperatively and returned to baseline levels after 1 month. ${ }^{5,22}$ This appears to be in line with current findings, with the exception that corneal staining levels did not return to extremely low preoperative baseline levels. Some studies reported persistent corneal staining for up to 6 months, 
which may not be explained by a decrease in tear secretion. Specifically, Wilson ${ }^{3}$ observed Rose Bengal staining patterns developing 1 to 3 months postoperatively that disappeared 6 months postoperatively, coinciding with the return of corneal sensation. ${ }^{27,28}$ Furthermore, Wilson reported no changes in tear secretion, indicating that staining was not a result of decreased tear production. ${ }^{3}$ He suggested that punctate epithelial erosions after surgery may be attributed to neurotrophic epitheliopathy.

\section{Comparison of lasers}

Generally, we did not identify significant differences in corneal sensation, tear stability, or corneal health, between VisuMax and IntraLase. One may have hypothesized that technical specifications, such as a nonapplanating docking surface, shorter pulse duration, higher repetition rate, and reduced laser pulse energy as well as the smaller flap size of VisuMax, may influence clinical outcome measures to a lesser extent as compared with IntraLase. ${ }^{29,30}$ The present study indicated that despite their technical differences, both platforms have relatively similar effects on the ocular surface.

There were a few limitations of the study. This present study was powered for refractive error outcomes, and the sample size may have been too low to show a statistical difference in clinical outcomes between the femtosecond laser platforms. Therefore, this study serves as a pilot study to appropriately calculate sample sizes for future studies.

The current study utilized 50-degree and 70-degree hinge angles for the VisuMax and IntraLase flaps, respectively. In our experience, optimal results for each platform have been achieved with the specified hinge angles. A different study tested the effect of 45-degree or 90-degree hinge angles on corneal sensitivity in femtosecond laser flaps, over a 12-month follow up period. ${ }^{5,22}$ The authors concluded that overall, hinge position and hinge angles had no effect on corneal sensation and dry eye sensations. ${ }^{5,22}$ In the current study, however, VisuMax and IntraLase hinge angles differed by 20 degrees, an amount that is a lot smaller than the 45-degree difference employed by the previous study. ${ }^{5}$

\section{Conclusion}

In summary, the present study found that the VisuMax and IntraLase femtosecond lasers did not affect the ocular surface system in a significantly different manner. We noted an ablation depth-dependent reduction in corneal sensitivity that persisted up to 3 months after surgery as well as diminished tear secretion and increased corneal staining at 1 week postoperatively. These findings suggest that the choice of a suitable femtosecond laser for a patient may be based on the surgeon's preference rather than any differential potential to cause dry eyes. However, a trend towards slightly lower reductions in corneal sensitivity and TBUT were observed in the VisuMax-operated eyes, which may be attributed to improved technical specifications.

\section{Acknowledgments}

This study was supported by a National Research FoundationFunded Translational and Clinical Research (TCR) Program grant [NMRC/TCR/002-SERI/2008-TCR 621/41/2008], Singapore.

Authors would like to thank Hla Myint Htoon (PhD) for statistical advice.

\section{Disclosure}

Authors report no conflict of interest in this work.

\section{References}

1. Duffey RJ, Leaming D. US trends in refractive surgery: 2004 ISRS/ AAO Survey. J Refract Surg. 2005;21(6):742-748.

2. Kalyvianaki MI, Katsanevaki VJ, Kavroulaki DS, Kounis GA, Detorakis ET, Pallikaris IG. Comparison of corneal sensitivity and tear function following Epi-LASIK or laser in situ keratomileusis for myopia. Am J Ophthalmol. 2006;142(4):669-671.

3. Wilson SE. Laser in situ keratomileusis-induced (presumed) neurotrophic epitheliopathy. Ophthalmology. 2001;108(6): $1082-1087$.

4. Lee BH, McLaren JW, Erie JC, Hodge DO, Bourne WM. Reinnervation in the cornea after LASIK. Invest Ophthalmol Vis Sci. 2002;43(12):3660-3664.

5. Mian SI, Li AY, Dutta S, Musch DC, Shtein RM. Dry eyes and corneal sensation after laser in situ keratomileusis with femtosecond laser flap creation Effect of hinge position, hinge angle, and flap thickness. $J$ Cataract Refract Surg. 2009;35(12):2092-2098.

6. Salomão MQ, Ambrósio R Jr, Wilson SE. Dry eye associated with laser in situ keratomileusis: Mechanical microkeratome versus femtosecond laser. J Cataract Refract Surg. 2009;35(10):1756-1760.

7. Chaurasia SS, Luengo Gimeno F, Tan K, et al. In vivo real-time intraocular pressure variations during LASIK flap creation. Invest Ophthalmol Vis Sci. 2010;51(9):4641-4645.

8. Yuen LH, Chan WK, Koh J, Mehta JS, Tan DT; Sing Lasik Research Group. A 10-year prospective audit of LASIK outcomes for myopia in 37,932 eyes at a single institution in Asia. Ophthalmology. 2010;117(6): $1236-1244$.

9. Rosman M, Hall RC, Chan CML, et al. Comparison of efficacy and safety of femtosecond LASIK using two different femtosecond laser platforms in contralateral eyes. $J$ Cataract Refract Surg. (In press).

10. Lee SJ, Kim JK, Seo KY, Kim EK, Lee HK. Comparison of corneal nerve regeneration and sensitivity between LASIK and laser epithelial keratomileusis (LASEK). Am J Ophthalmol. 2006;141(6):1009-1015.

11. Bragheeth MA, Dua HS. Corneal sensation after myopic and hyperopic LASIK: clinical and confocal microscopic study. $\mathrm{Br} J$ Ophthalmol. 2005;89(5):580-585.

12. Patel SV, McLaren JW, Kittleson KM, Bourne WM. Subbasal nerve density and corneal sensitivity after laser in situ keratomileusis: femtosecond laser vs mechanical microkeratome. Arch Ophthalmol. 2010;128(11):1413-1419. 
13. Nassaralla BA, McLeod SD, Nassaralla JJ Jr. Effect of myopic LASIK on human corneal sensitivity. Ophthalmology. 2003;110(3):497-502.

14. Sekundo W, Kunert KS, Blum M. Small incision corneal refractive surgery using the small incision lenticule extraction (SMILE) procedure for the correction of myopia and myopic astigmatism: results of a 6 month prospective study. Br J Ophthalmol. 2011;95(3):335-339.

15. Ang RT, Dartt DA, Tsubota K. Dry eye after refractive surgery. Curr Opin Ophthalmol. 2001;12(4):318-322.

16. Donnenfeld ED, Solomon K, Perry HD, et al. The effect of hinge position on corneal sensation and dry eye after LASIK. Ophthalmology. 2003;110(5):1023-1029.

17. Barequet IS, Hirsh A, Levinger S. Effect of thin femtosecond LASIK flaps on corneal sensitivity and tear function. $J$ Refract Surg. 2008;24(9):897-902.

18. Tanaka M, Takano Y, Dogru M, et al. Effect of preoperative tear function on early functional visual acuity after laser in situ keratomileusis. J Cataract Refract Surg. 2004;30(11):2311-2315.

19. Lee JB, Ryu CH, Kim J, Kim EK, Kim HB. Comparison of tear secretion and tear film instability after photorefractive keratectomy and laser in situ keratomileusis. J Cataract Refract Surg. 2000;26(9):1326-1331.

20. Nejima R, Miyata K, Tanabe T, et al. Corneal barrier function, tear film stability, and corneal sensation after photorefractive keratectomy and laser in situ keratomileusis. Am J Ophthalmol. 2005;139(1):64-71.

21. Yu EY, Leung A, Rao S, Lam DS. Effect of laser in situ keratomileusis on tear stability. Ophthalmology. 2000;107(12):2131-2135.

22. Mian SI, Shtein RM, Nelson A, Musch DC. Effect of hinge position on corneal sensation and dry eye after laser in situ keratomileusis using a femtosecond laser. J Cataract Refract Surg. 2007;33(7):1190-1194.
23. Goto T, Zheng X, Klyce SD, et al. Evaluation of the tear film stability after laser in situ keratomileusis using the tear film stability analysis system. Am J Ophthalmol. 2004;137(1):116-120.

24. Foo SK, Kaur S, Abd Manan F, Low AJ. The changes of tear status after conventional and wavefront-guided intraLASIK. Malays $J$ Med Sci. 2011;18(2):32-39.

25. Rodriguez-Prats JL, Hamdi IM, Rodriguez AE, Galal A, Alio JL. Effect of suction ring application during LASIK on goblet cell density. $J$ Refract Surg. 2007;23(6):559-562.

26. Konomi K, Chen LL, Tarko RS, et al. Preoperative characteristics and a potential mechanism of chronic dry eye after LASIK. Invest Ophthalmol Vis Sci. 2008;49(1):168-174.

27. Linna TU, Vesaluoma MH, Pérez-Santonja JJ, Petroll WM, Alió JL, Tervo TM. Effect of myopic LASIK on corneal sensitivity and morphology of subbasal nerves. Invest Ophthalmol Vis Sci. 2000;41(2): 393-397.

28. Rodriguez AE, Rodriguez-Prats JL, Hamdi IM, Galal A, Awadalla M, Alio JL. Comparison of goblet cell density after femtosecond laser and mechanical microkeratome in LASIK. Invest Ophthalmol Vis Sci. 2007;48(6):2570-2575.

29. de Medeiros FW, Kaur H, Agrawal V, et al. Effect of femtosecond laser energy level on corneal stromal cell death and inflammation. J Refract Surg. 2009;25(10):869-874.

30. Netto MV, Mohan RR, Medeiros FW, et al. Femtosecond laser and microkeratome corneal flaps: comparison of stromal wound healing and inflammation. J Refract Surg. 2007;23(7):667-676.
Clinical Ophthalmology

\section{Publish your work in this journal}

Clinical Ophthalmology is an international, peer-reviewed journal covering all subspecialties within ophthalmology. Key topics include: Optometry; Visual science; Pharmacology and drug therapy in eye diseases; Basic Sciences; Primary and Secondary eye care; Patient Safety and Quality of Care Improvements. This journal is indexed on

\section{Dovepress}

PubMed Central and CAS, and is the official journal of The Society of Clinical Ophthalmology (SCO). The manuscript management system is completely online and includes a very quick and fair peer-review system, which is all easy to use. Visit http://www.dovepress.com/ testimonials.php to read real quotes from published authors. 